\title{
Comparative analysis of genes regulated in acute myelomonocytic leukemia with and without inv(16)(p13q22) using microarray techniques, real-time PCR, immunohistochemistry, and flow cytometry immunophenotyping
}

Xiaoping Sun ${ }^{1}$, Wei Zhang ${ }^{1}$, Latha Ramdas ${ }^{1}$, David N Stivers ${ }^{2}$, Daniel M Jones ${ }^{3}$, Hagop M Kantarjian ${ }^{4}$, Elihu H Estey ${ }^{5}$, Saroj Vadhan-Raj ${ }^{4}$, L Jeffrey Medeiros ${ }^{3}$ and Carlos E Bueso-Ramos ${ }^{3}$

${ }^{1}$ Division of Pathology and Laboratory Medicine, The University of Texas MD Anderson Cancer Center, Houston, TX, USA; ${ }^{2}$ Department of Bioinformatics and Computational Biology, The University of Texas MD Anderson Cancer Center, Houston, TX, USA ${ }^{3}$ Department of Hematopathology, The University of Texas MD Anderson Cancer Center, Houston, TX, USA; ${ }^{4}$ Department of Cytokine and Supportive Oncology, The University of Texas MD Anderson Cancer Center, Houston, TX, USA and ${ }^{5}$ Department of Leukemia, The University of Texas MD Anderson Cancer Center, Houston, TX, USA

Acute myeloid leukemia with inv(16)(p13q22), also known as M4Eo, is a distinct type of leukemia with characteristic clinicopathologic and cytogenetic features. Patients with M4Eo have monocytosis, high blast counts, and abnormal bone marrow eosinophils that contain large basophilic granules. The inv(16)(p13q22) or, less commonly, the $t(16 ; 16)(p 13 ; q 22)$ causes fusion of the $C B F \beta$ gene at $16 q 22$ and the $M Y H 11$ gene at 16p13, creating the novel chimeric protein $\operatorname{CBF} \beta$-MYH11. To understand the underlying molecular mechanisms unique to M4Eo biology, we determined the gene expression profile of M4Eo cases by using cDNA and long oligonucleotide microarrays. Cases of acute myelomonocytic leukemia without $C B F \beta-M Y H 11$ (M4) acted as our control. We found that in the gene expression profile of M4Eo, NF- $\kappa$ B activators and inhibitors were upregulated and downregulated, respectively, suggesting that the NF- $\kappa$ B signaling pathway is activated at a higher level in M4Eo than in acute myelomonocytic leukemia M4. In addition, the gene expression profile of M4Eo indicates high cell proliferation and low apoptosis. We used real-time PCR, immunohistochemistry, and flow cytometry immunophenotyping to confirm some of our microarray data. These findings most likely represent the functional consequences of the abnormal chimeric protein CBF $\beta$-MYH11, which is unique to this disease, and suggest that NF- $\kappa$ B is a potential therapeutic target for treating M4Eo patients.

Modern Pathology (2007) 20, 811-820; doi:10.1038/modpathol.3800829; published online 15 June 2007

Keywords: $\mathrm{CBF} \beta$-MYH11; inv(16); leukemia; NF- $\kappa \mathrm{B}$; gene expression; M4Eo

Acute myeloid leukemia with inv(16)(p13q22), or rarely $\mathrm{t}(16 ; 16)(\mathrm{p} 13 ; \mathrm{q} 22)$, has distinctive morphologic, cytogenetic, and clinical features. ${ }^{1}$ Previously

Correspondence: Dr CE Bueso-Ramos, MD, PhD, Department of Hematopathology, Unit 72, The University of Texas MD Anderson Cancer Center, 1515 Holcombe Boulevard, Houston, TX 77030 USA.

E-mail: cbuesora@mdanderson.org

Received 18 January 2007; revised 17 April 2007; accepted 18 April 2007; published online 15 June 2007 known as M4Eo in the French-American-British (FAB) classification, ${ }^{2}$ this neoplasm is now defined in the World Health Organization classification by its cytogenetic and molecular abnormalities. ${ }^{1}$ In addition to a high blast count, M4Eo is characterized by monocytosis and eosinophilia with abnormal bone marrow eosinophils that contain large basophilic granules. $^{3-5}$ The presence of abnormal bone marrow eosinophils morphologically distinguishes M4Eo from its counterpart, acute myelomonocytic leukemia (also known as FAB M4), which lacks 
eosinophilia and has no distinct cytogenetic abnormality.

The presence of inv(16)(p13q22) or $\mathrm{t}(16 ; 16)$ (p13;q22) results in the fusion of two genes: the core binding factor $\beta$ gene $(C B F \beta)$ at $16 \mathrm{q} 22$, which encodes the $\beta$-subunit of the CBF, and the MYH11 gene at $16 \mathrm{p} 13$, which encodes the smooth muscle myosin heavy chain. ${ }^{6}$ The chimeric gene $C B F \beta$ $M Y H 11$ fuses most of the $5^{\prime}$ coding region of $C B F \beta$ in frame with the $3^{\prime}$ portion of $M Y H 11$, resulting in the production of the chimeric protein CBF $\beta$-MYH11 in leukemic cells $s^{7,8}$ and abnormal eosinophils, indicating that the latter also derive from the leukemic clone. $^{9}$ Cytogenetically, the $C B F \beta-M Y H 11$ fusion gene may be associated with trisomy 8,21 , and 22 and, less frequently, with deletion of chromosome $7 \mathrm{q} \cdot{ }^{10-12} \mathrm{CBF} \beta$ is essential for the generation of hematopoietic stem and progenitor cells, and CBF $\beta$-MYH11 blocks embryonic hematopoiesis at the stem-progenitor cell stage. ${ }^{13}$ The role of CBF $\beta$ MYH11 in leukemogenesis remains unknown (see review by Shigesada et $a l^{14}$ ). We previously reported that M4Eo cells have a high growth fraction and low rate of apoptosis. ${ }^{11}$

Gene expression profiling is a powerful tool in characterizing gene expression on a broad scale for various neoplasms. Most acute myeloid leukemia studies to date, however, have focused on the diagnosis and classification of closely related groups of malignancies. ${ }^{15,16}$ In this study, we used cDNA microarrays to determine the gene expression profile of M4Eo, focusing on the underlying molecular mechanisms of M4Eo associated with the $C B F \beta$ MYH11 fusion gene.

\section{Materials and methods}

To understand the gene expression profile of M4Eo tumor cells and microenvironment, and particularly the gene expression attributable to $C B F \beta-M Y H 11$, we compared cases of M4Eo with those of the type of acute myeloid leukemia it most closely resembles, acute myelomonocytic leukemia, without $C B F \beta$ MYH11, M4. This approach differs from other studies of acute myelomonocytic leukemia M4 that used benign monocytes as a control (an approach that assesses gene expression in all types of acute myelomonocytic leukemia) or that compared various types of acute myeloid leukemia with human leukemic cell lines, normal donor CD34-positive hematopoietic cells, or other acute myeloid leukemia types.

We obtained bone marrow aspiration specimens with uniform RNA processing within $1 \mathrm{~h}$ of sample acquisition from patients who had been diagnosed with M4Eo or acute myelomonocytic leukemia M4 ${ }^{1}$ at The University of Texas MD Anderson Cancer Center between August 1998 and August 2003. We analyzed 18 M4Eo cases with a cDNA microarray and further analyzed 7 of these cases that had sufficient RNA with a long oligonucleotide (75-mer) microarray, referred to subsequently as the Pathway microarray. Real-time quantitative reverse transcriptase-polymerase chain reaction (RT-PCR) was performed on 17 M4Eo cases, of which 11 were tested using the cDNA microarray and 1 was tested using both microarrays. Pooled RNA from 20 cases of acute myelomonocytic leukemia M4 was used as the control. The University of Texas MD Anderson Cancer Center Institutional Review Board approved this study.

Total RNA was isolated from fresh bone marrow aspiration specimens using TRIzol reagent (Invitrogen Corp, Carlsbad, CA, USA) and assessed for RNA quality with Agilent Bioanalyzer (Agilent Technologies, Palo Alto, CA, USA). For the control, pooled RNA was prepared by mixing the same amount of total RNA from 20 individual acute myelomonocytic leukemia M4 patient samples. We hybridized the pooled RNA on a cDNA microarray (manufactured by the Cancer Genomic Core Laboratory, MDACC) that contained 4704 genes in duplicate with controls. Seven of the 18 M4Eo cases were also analyzed with the Pathway microarray, which contained 1500 functionally well-characterized genes involved in various signaling pathways important for cancer biology.

The Supplementary Information details the following procedures: RNA isolation and microarray hybridization, statistical methods for gene expression analysis, analysis for the combination of data sets, RT-PCR, conventional cytogenetics, fluorescence in situ hybridization, flow cytometry immunophenotyping, and immunohistochemistry.

\section{Results}

Table 1 provides the detailed clinical and pathologic features of the 18 patients with M4Eo. The patients included nine women and nine men and had a median age of 41 years with a range of 21-74 years; five patients were 50 years or older. None of the patients had received therapy. The complete remission rate and relapse-free survival time of the patients with M4Eo included in this study were not significantly different from those of other patients with M4Eo treated during the same period at this cancer center.

The median percentage of bone marrow blasts in the M4Eo cases was $61 \%$, as determined by WrightGiemsa staining. The M4Eo cases and the acute myelomonocytic leukemia M4 control had similar median numbers of blasts. Of the 18 M4Eo cases, 11 had eosinophilia ( $>4 \%$ ), whereas none of the 20 acute myelomonocytic leukemia M4 cases had eosinophilia. Cytochemical stains using bone marrow aspirate smears showed that in all cases, the M4Eo and acute myelomonocytic leukemia M4 blasts were strongly and uniformly positive for myeloperoxidase and variably positive for butyrate esterase. 
Table 1 Clinical, cytogenetic, and bone marrow morphologic features of M4Eo patients

\begin{tabular}{|c|c|c|c|c|c|c|}
\hline $\begin{array}{l}\text { Case } \\
\text { no./sex/age (y) }\end{array}$ & $\begin{array}{l}c D N A \\
\text { microarray }\end{array}$ & $\begin{array}{l}\text { Pathway } \\
\text { microarray }\end{array}$ & $\begin{array}{l}\text { Other cytogenetics } \\
\quad \text { finding }\end{array}$ & $\begin{array}{l}\text { Blast } \\
(\%)\end{array}$ & $\begin{array}{c}\text { Eosinophil } \\
(\%)\end{array}$ & Treatment \\
\hline 1/M/38 & Yes & No & No & 45 & 21 & Fludarabine, cytarabine \\
\hline $2 / F / 28$ & Yes & Yes & No & 53 & 19 & Cyclophosphamide, cytarabine, topotecan \\
\hline $3 / \mathrm{M} / 41$ & Yes & No & +22 & 62 & 0 & Fludarabine, cytarabine \\
\hline 4/M/59 & Yes & No & No & 57 & 8 & Fludarabine, cytarabine \\
\hline $5 / \mathrm{M} / 74$ & Yes & No & No & 32 & 0 & Fludarabine, cytarabine \\
\hline 6/M/52 & Yes & No & $+22,-10,-13$ & 46 & 1 & Fludarabine, cytarabine \\
\hline 7/M/52 & Yes & No & No & 64 & 3 & Fludarabine, cytarabine \\
\hline $8 / F / 43$ & Yes & No & No & 49 & 32 & Fludarabine, cytarabine \\
\hline 9/M/52 & Yes & No & No & 70 & 11 & Fludarabine, cytarabine \\
\hline 10/F/37 & Yes & No & +8 & 66 & 15 & Cytarabine, anthracycline \\
\hline $11 / \mathrm{F} / 44$ & Yes & No & +22 & 69 & 4 & Idarubicin, cytarabine \\
\hline $12 / F / 63$ & Yes & Yes & +22 & 79 & 8 & Cyclophosphamide, cytarabine, topotecan \\
\hline $13 / F / 21$ & Yes & No & +22 & 44 & 0 & Idarubicin, cytarabine \\
\hline $14 / \mathrm{M} / 29$ & Yes & Yes & $+9,+22,-18$ & 61 & 10 & Daunorubicin, cytarabine \\
\hline $15 / F / 23$ & Yes & Yes & No & 52 & 20 & Fludarabine, cytarabine \\
\hline $16 / F / 21$ & Yes & Yes & No & 70 & 4 & Fludarabine, cytarabine \\
\hline $17 / F / 39$ & Yes & Yes & No & 74 & 10 & Fludarabine, cytarabine \\
\hline $18 / \mathrm{M} / 42$ & Yes & Yes & No & 64 & 9 & Fludarabine, cytarabine \\
\hline
\end{tabular}

Table 2a Top differentially expressed genes in M4Eo compared with M4 from the cDNA microarray

\begin{tabular}{|c|c|c|c|}
\hline Name & Symbol & Fold change & $\mathrm{P}$-value \\
\hline Transmembrane $4 \mathrm{~L}$ six family member 4 & TM4SF4 & 3.76 & $5.58 \mathrm{E}-06$ \\
\hline Thyrotropin-releasing hormone & $\mathrm{TRH}$ & 3.45 & 7.31E-05 \\
\hline Integral membrane protein $2 \mathrm{~A}$ & ITM2A & 3.41 & 3.35E-06 \\
\hline Cytochrome P450, family 2, subfamily E, polypeptide 1 & CYP2E1 & 3.34 & 4.35E-05 \\
\hline Homo sapiens actin filament associated protein (AFAP), transcript variant 1 , mRNA & AFAP & 3.29 & $1.27 \mathrm{E}-05$ \\
\hline Prostaglandin D2 synthase, hematopoietic & PGDS & 3.26 & $8.68 \mathrm{E}-06$ \\
\hline Low-density lipoprotein-related protein 2 & LRP2 & 3.14 & $3.55 \mathrm{E}-05$ \\
\hline ATP-binding cassette, sub-family G (WHITE), member 1 & ABCG1 & 3.11 & $9.82 \mathrm{E}-05$ \\
\hline Frizzled-related protein & FRZB & 3.06 & $3.43 \mathrm{E}-05$ \\
\hline Prepronociceptin & PNOC & 2.95 & $9.63 \mathrm{E}-05$ \\
\hline Suppression of tumorigenicity 18 (breast carcinoma) (zinc finger protein) & ST18 & 2.95 & $1.25 \mathrm{E}-04$ \\
\hline Prodynorphin & PDYN & 2.88 & $6.64 \mathrm{E}-05$ \\
\hline Lumican & LUM & 2.85 & $1.71 \mathrm{E}-04$ \\
\hline G-protein-coupled receptor 19 & GPR19 & 2.84 & $3.86 \mathrm{E}-05$ \\
\hline Nuclear factor of kappa light polypeptide gene enhancer in B-cells inhibitor, alpha & NFKBIA & -2.37 & $6.43 \mathrm{E}-05$ \\
\hline Pre-B-cell leukemia transcription factor 3 & PBX3 & -2.44 & $6.57 \mathrm{E}-05$ \\
\hline acyl-CoA synthetase long-chain family member 1 & ACSL1 & -2.47 & $1.01 \mathrm{E}-04$ \\
\hline ADP-ribosylation factor-like 4A & ARL4A & -2.51 & $2.66 \mathrm{E}-05$ \\
\hline Collagen, type IV, alpha 5 (Alport syndrome) & COL4A5 & -2.63 & 3.73E-05 \\
\hline CD163 antigen & CD163 & -2.67 & $6.38 \mathrm{E}-05$ \\
\hline Golgin-67 & GOLGIN-67 & -2.73 & $1.45 \mathrm{E}-05$ \\
\hline Meis1, myeloid ecotropic viral integration site 1 homolog (mouse) & MEIS1 & -2.74 & $1.04 \mathrm{E}-06$ \\
\hline Carbonic anhydrase II & CA2 & -2.85 & 4.76E-05 \\
\hline Carbonic anhydrase I & CA1 & -2.91 & $1.74 \mathrm{E}-04$ \\
\hline Transcription factor 2, hepatic; LF-B3; variant hepatic nuclear factor & TCF2 & -2.95 & 7.37E-05 \\
\hline Chondroitin sulfate proteoglycan 2 (versican) & CSPG2 & -3.10 & $1.79 \mathrm{E}-05$ \\
\hline CD36 antigen (collagen type I receptor, thrombospondin receptor) & CD36 & -3.21 & $7.58 \mathrm{E}-06$ \\
\hline Spermidine/spermine N1-acetyltransferase & SAT & -3.27 & $3.01 \mathrm{E}-06$ \\
\hline Defensin, alpha 4 , corticostatin & DEFA4 & -4.74 & $1.33 \mathrm{E}-05$ \\
\hline Hemoglobin, epsilon 1 & HBE1 & -5.11 & $6.05 \mathrm{E}-05$ \\
\hline
\end{tabular}

\section{M4Eo has a Distinct Gene Expression Profile}

As described in Materials and methods, the two microarrays used have many shared genes and many unique genes, enabling us to compare the results of the shared genes and to obtain compensatory data for those present in only one microarray. Tables 2a and $b$ present a list of the most differentially expressed genes for each microarray; Supplementary Figure 1 presents representative genes from this group. These lists are derived from a longer list of genes that were significantly differentially expressed based on a set false discovery rate (FDR). Between the M4Eo cases and acute myelomonocytic 
Table 2b Top differentially expressed genes in M4Eo compared with M4 from the Pathway microarray

\begin{tabular}{|c|c|c|c|}
\hline Name & Symbol & Fold change & $\mathrm{P}$-value \\
\hline Secreted protein, acidic, cysteine-rich (osteonectin) & SPARC & 6.00 & $1.24 \mathrm{E}-05$ \\
\hline Epithelial membrane protein 1 & EMP1 & 3.15 & 5.73E-03 \\
\hline CD34 antigen & CD34 & 2.66 & $1.59 \mathrm{E}-03$ \\
\hline Human mRNA for hepatocyte growth factor (HGF) & HSHGF & 2.63 & 3.34E-05 \\
\hline Interferon regulatory factor 4 & IRF4 & 2.59 & $6.53 \mathrm{E}-03$ \\
\hline Cyclin D2 & CCND2 & 2.59 & $9.50 \mathrm{E}-06$ \\
\hline V-kit Hardy-Zuckerman 4 feline sarcoma viral oncogene homolog & KIT & 2.17 & $2.10 \mathrm{E}-02$ \\
\hline B-cell CLL/lymphoma 2 & BCL2 & 2.02 & $3.26 \mathrm{E}-02$ \\
\hline Interleukin 1, alpha & IL1A & 2.01 & $6.36 \mathrm{E}-03$ \\
\hline Integrin, alpha 6 & ITGA6 & 1.98 & $3.68 \mathrm{E}-04$ \\
\hline Protein tyrosine phosphatase, receptor type, K & PTPRK & 1.98 & 6.17E-03 \\
\hline Retinoblastoma 1 (including osteosarcoma) & RB1 & 1.91 & $7.24 \mathrm{E}-03$ \\
\hline Integrin, alpha 6 & ITGA6 & 1.91 & $3.32 \mathrm{E}-03$ \\
\hline Early growth response 1 & EGR1 & 1.85 & $2.27 \mathrm{E}-02$ \\
\hline EPH receptor A7 & EPHA7 & 1.85 & $2.05 \mathrm{E}-02$ \\
\hline Superoxide dismutase 2 , mitochondrial & SOD2 & -1.97 & $4.68 \mathrm{E}-02$ \\
\hline Inhibitor of DNA binding 2 , dominant negative helix-loop-helix protein & ID2 & -2.02 & $1.06 \mathrm{E}-02$ \\
\hline Coagulation factor III (thromboplastin, tissue factor) & F3 & -2.03 & 1.67E-02 \\
\hline Receptor-interacting serine-threonine kinase 3 & RIPK3 & -2.14 & $1.22 \mathrm{E}-02$ \\
\hline Cathepsin L & CTSL & -2.17 & $1.24 \mathrm{E}-02$ \\
\hline DNA-damage-inducible transcript 3 & DDIT3 & -2.44 & $2.39 \mathrm{E}-03$ \\
\hline \multirow{2}{*}{\multicolumn{4}{|c|}{6 (Golgin linked to PML) (Golgin-like protein) }} \\
\hline & & & \\
\hline Hemopoietic cell kinase & HCK & -2.45 & $1.88 \mathrm{E}-02$ \\
\hline Growth arrest-specific 2 & GAS2 & -2.48 & $2.02 \mathrm{E}-04$ \\
\hline Gardner-Rasheed feline sarcoma viral (v-fgr) oncogene homolog & FGR & -2.57 & $2.13 \mathrm{E}-02$ \\
\hline Growth differentiation factor 15 & GDF15 & -2.80 & 5.63E-03 \\
\hline Protein kinase, cAMP-dependent, regulatory, type II, beta & PRKAR2B & -3.10 & $3.84 \mathrm{E}-03$ \\
\hline Pre-B-cell leukemia transcription factor 3 & PBX3 & -3.71 & $2.28 \mathrm{E}-05$ \\
\hline Suppressor of cytokine signaling 2 & SOCS2 & -4.57 & 7.37E-04 \\
\hline Amphiregulin (schwannoma-derived growth factor) & AREG & -5.15 & $3.98 \mathrm{E}-03$ \\
\hline
\end{tabular}

leukemia M4 control, the genes identified from the cDNA microarray had a fold change in expression level of at least 2.37 (either increase or decrease) and significant $P$-values $(<0.001)$ at an FDR of 0.001 (Table 2a), and those identified from the Pathway microarray had a fold change of at least 1.85 and significant $P$-values $(<0.05)$ at an FDR of 0.05 (Table 2b). Much more stringent cut-offs were used for the cDNA microarray because there were more genes and more samples than for the Pathways array. As expected, the most significantly differentially expressed genes on the cDNA microarray are functionally diverse, whereas the most significantly differentially expressed genes in the Pathway microarray are involved in signal transduction pathways. Supplementary Tables $2 \mathrm{a}$ and b provide an extended version of the differentially expressed genes in the cDNA and Pathway microarrays. We did not find a correlation between gene expression profile and the number of blasts. In all cases, numerous blasts were present.

Pre-B-cell leukemia transcription factor $3 \mathrm{~A}$ $(P B X 3)$ is one of the significantly differentially expressed genes in both the cDNA and Pathway microarrays and was downregulated in both microarrays $(-2.44-$ and -3.71 -fold in the cDNA and Pathway microarrays, respectively; Tables 2a and b). This gene is highly homologous to $P B X 1$, a human homeobox gene involved in $\mathrm{t}(1 ; 19)$-positive acute
pre-B-cell lymphoblastic leukemia. ${ }^{17}$ Table 2c shows a few of the top differentially expressed genes present in both microarrays. Supplementary Table 2c gives a complete list of such genes.

As expected, the expression levels of the two genes involved in the inv(16) or $\mathrm{t}(16 ; 16)$ in M4Eo, $C B F \beta$ and $M Y H 11$, differed between the M4Eo cases and the control. $C B F \beta$ had lower expression levels in the M4Eo cases in both microarrays $(-1.64-$ and -1.45-fold in the cDNA and the Pathway microarrays, respectively), whereas MYH11 had slightly higher expression levels in the M4Eo cases $(+1.07-$ fold in the cDNA microarray; data not shown). We expected the $C B F \beta$ clone (NM_001755) on the cDNA microarray and the $C B F \beta$ 70-mer oligo (corresponding to the sequence from nucleotide $733-802$ in NM_001755) on the Pathway microarray to hybridize minimally, if at all, to the chimeric $C B F \beta$ MYH11 gene according to the common location of the inv(16) breakpoints. ${ }^{18}$ However, the MYH11 clone (AA126989) on the cDNA microarray contained a sequence that could hybridize solely to the chimeric gene. Therefore, the signal intensity of MYH11 represented the expression level of the chimeric gene. Immunohistochemical analysis of the $\mathrm{CBF} \beta$-MYH11 protein revealed a unique nuclear localization in our M4Eo cases. ${ }^{19}$

ITM2A, a novel type II integral membrane protein gene that is involved in T-cell development and 
Table 2c Top differentially expressed genes that were present in both the cDNA and Pathway microarrays

\begin{tabular}{|c|c|c|c|c|c|}
\hline Name & Symbol & $\begin{array}{l}\text { Fold change } \\
\quad(c D N A)\end{array}$ & $\begin{array}{l}\text { Fold change } \\
\text { (pathway) }\end{array}$ & $\begin{array}{l}\mathrm{P}-\text { value* } \\
(c D N A)\end{array}$ & $\begin{array}{l}\text { P-value* } \\
\text { (pathway) }\end{array}$ \\
\hline Epithelial membrane protein 1 & EMP1 & 2.31 & 3.15 & $2.36 \mathrm{E}-05$ & $5.73 \mathrm{E}-03$ \\
\hline Integrin, alpha 6 & ITGA6 & 1.75 & 1.98 & $2.43 \mathrm{E}-04$ & $3.68 \mathrm{E}-04$ \\
\hline Src family associated phosphoprotein 1 & SCAP1 & 2.22 & 1.75 & 7.93E-05 & $1.93 \mathrm{E}-02$ \\
\hline B-cell CLL/lymphoma 2 & BCL2 & 1.74 & 1.71 & $1.22 \mathrm{E}-04$ & 2.03E-03 \\
\hline Interferon regulatory factor 4 & IRF4 & -1.78 & 1.69 & 6.15E-05 & $6.46 \mathrm{E}-03$ \\
\hline Vascular cell adhesion molecule 1 & VCAM1 & 2.32 & 1.57 & $1.18 \mathrm{E}-05$ & $9.11 \mathrm{E}-03$ \\
\hline Interferon regulatory factor 2 & IRF2 & 1.18 & 1.42 & $1.54 \mathrm{E}-02$ & $5.62 \mathrm{E}-04$ \\
\hline Echinoderm microtubule-associated protein-like 1 & EML1 & 1.89 & 1.38 & 7.45E-05 & $4.82 \mathrm{E}-02$ \\
\hline Wilms tumor 1 & WT1 & 1.54 & 1.33 & 2.99E-04 & $1.65 \mathrm{E}-02$ \\
\hline Estrogen receptor 1 & ESR1 & 2.42 & 1.30 & $1.22 \mathrm{E}-05$ & $4.50 \mathrm{E}-02$ \\
\hline EPH receptor A1 & EPHA1 & 1.91 & 1.20 & 1.50E-04 & $2.64 \mathrm{E}-02$ \\
\hline Plasminogen activator, urokinase & PLAU & 1.57 & 1.16 & $2.60 \mathrm{E}-04$ & $2.34 \mathrm{E}-02$ \\
\hline Protocadherin 1 (cadherin-like 1) & PCDH1 & 1.88 & 1.15 & $2.60 \mathrm{E}-04$ & $1.61 \mathrm{E}-02$ \\
\hline $\begin{array}{l}\text { Fibroblast growth factor receptor } 1 \text { (fms-related tyrosine } \\
\text { kinase 2, Pfeiffer syndrome) }\end{array}$ & FGFR1 & 2.80 & 1.09 & $5.41 \mathrm{E}-06$ & $2.01 \mathrm{E}-02$ \\
\hline Cytochrome c oxidase subunit VIa polypeptide 1 & COX6A1 & -1.26 & -1.24 & $2.45 \mathrm{E}-03$ & $1.71 \mathrm{E}-03$ \\
\hline Protein phosphatase 2 (formerly $2 \mathrm{~A}$ ), catalytic subunit, alpha isoform & PPP2CA & -1.33 & -1.30 & $8.52 \mathrm{E}-05$ & $1.45 \mathrm{E}-02$ \\
\hline Pleckstrin & PLEK & -1.84 & -1.32 & 3.04E-04 & $1.31 \mathrm{E}-02$ \\
\hline Non-metastatic cells 2, protein (NM23B) expressed in & NME2 & -1.84 & -1.33 & $1.88 \mathrm{E}-04$ & $1.55 \mathrm{E}-02$ \\
\hline Ras homolog gene family, member A & RHOA & -1.53 & -1.35 & $6.85 \mathrm{E}-05$ & 8.13E-03 \\
\hline Splicing factor 1 & SF1 & -1.53 & -1.37 & 2.37E-04 & 8.99E-04 \\
\hline Vimentin & VIM & -2.28 & -1.45 & $1.75 \mathrm{E}-05$ & $3.30 \mathrm{E}-02$ \\
\hline Jun D proto-oncogene & JUND & -2.36 & -1.58 & $1.82 \mathrm{E}-05$ & $3.98 \mathrm{E}-02$ \\
\hline Protein kinase $\mathrm{C}$, delta & PRKCD & -1.67 & -1.59 & $1.21 \mathrm{E}-04$ & $5.17 \mathrm{E}-03$ \\
\hline Adenosine kinase & ADK & -1.34 & -1.63 & 3.08E-02 & 1.06E-03 \\
\hline Pim-1 oncogene & PIM1 & -1.91 & -1.74 & $2.94 \mathrm{E}-04$ & 4.19E-03 \\
\hline $\begin{array}{l}\text { Nuclear factor of kappa light polypeptide gene enhancer } \\
\text { in B-cells inhibitor, alpha }\end{array}$ & NFKBIA & -2.37 & -1.75 & $6.43 \mathrm{E}-05$ & $4.81 \mathrm{E}-02$ \\
\hline CD97 antigen & CD97 & -1.62 & -1.76 & $3.56 \mathrm{E}-05$ & $9.34 \mathrm{E}-03$ \\
\hline Glyceraldehyde-3-phosphate dehydrogenase & GAPD & -1.51 & -1.78 & $2.98 \mathrm{E}-04$ & $1.94 \mathrm{E}-02$ \\
\hline Cyclin D3 & CCND3 & -2.28 & -1.87 & $2.68 \mathrm{E}-05$ & $6.70 \mathrm{E}-04$ \\
\hline Hemopoietic cell kinase & HCK & -1.82 & -2.45 & $2.34 \mathrm{E}-04$ & $1.88 \mathrm{E}-02$ \\
\hline Growth arrest-specific 2 & GAS2 & 1.47 & -2.48 & $4.50 \mathrm{E}-02$ & $2.02 \mathrm{E}-04$ \\
\hline Pre-B-cell leukemia transcription factor 3 & PBX3 & -2.44 & -3.71 & $6.57 \mathrm{E}-05$ & $2.28 \mathrm{E}-05$ \\
\hline
\end{tabular}

${ }^{*} P$ values $<0.05$.

activation, ${ }^{20}$ myogenesis, ${ }^{21}$ and chondrogenesis ${ }^{22}$ was a good marker of M4Eo in this study. The expression levels of ITM2A were higher in all 18 M4Eo cases in the cDNA microarray $(+3.41$-fold; Table 2a). Similarly, by RT-PCR, the expression levels of ITM2A were higher in all 17 M4Eo cases tested than in the control (median +8.24 -fold; range +1.5 - to +40 -fold; Supplementary Figure 2).

\section{NF- $\kappa$ B is Dysregulated in M4Eo}

One of the top differentially expressed genes was $N F-\kappa B I A$, which encodes an inhibitor of $N F-\kappa \mathrm{B}$ $(\mathrm{I} \kappa \mathrm{B}){ }^{23}$ We found lower expression levels of $\mathrm{NF}$ $\kappa B I A(-2.37-$ and -1.75 -fold in the cDNA and Pathway microarrays, respectively) in the M4Eo cases compared with the control (Table 2c). TNFAIP3 (TNF $\alpha$-induced protein 3), which is also an inhibitor of NF- $\kappa \mathrm{B},{ }^{24}$ had lower expression levels in the M4Eo cases $(-1.59$-fold in the cDNA microarray (data not shown) and -1.77 in the Pathway microarray; Supplementary Table 2b). In contrast, TNFRSF (TNFR superfamily) members 11a (a receptor activator of NF- $\kappa$ B (RANK) ${ }^{25,26}$ ) and $11 \mathrm{~b}$ had higher expression levels in the M4Eo cases $(+2.39$-fold in the cDNA microarray for TNFRSF $11 b$ (Supplementary Table 2a) and +2.27-fold for TNFRSF11a in the Pathway microarray (data not shown).

In our earlier retrospective study, we observed that NF- $\kappa \mathrm{B}$ was constitutively activated in M4Eo. ${ }^{27}$ To validate whether NF- $\kappa$ B was activated, we used immunohistochemistry to assess NF- $\kappa \mathrm{B}$ p65 in an additional series of M4Eo cases and acute myelomonocytic leukemia M4 controls (Figure 1a and b). Nuclear localization of the protein indicates its activation. We found that the nuclear immunoreactivity of NF- $\kappa \mathrm{B}$ p65 was significantly higher in 49 M4Eo cases (median 37\%, range 5-82\%) compared with 35 acute myelomonocytic leukemia M4 cases (median 11\%, range $1-88 \%)(P<0.001)$ (Table 3 ).

\section{Genes Involved in Cell Proliferation are Differentially Expressed in M4Eo}

Cyclin D2 (CCND2) was among the most differentially expressed genes in the Pathway microarray $(+2.59$-fold; Table 2b). We confirmed this with 


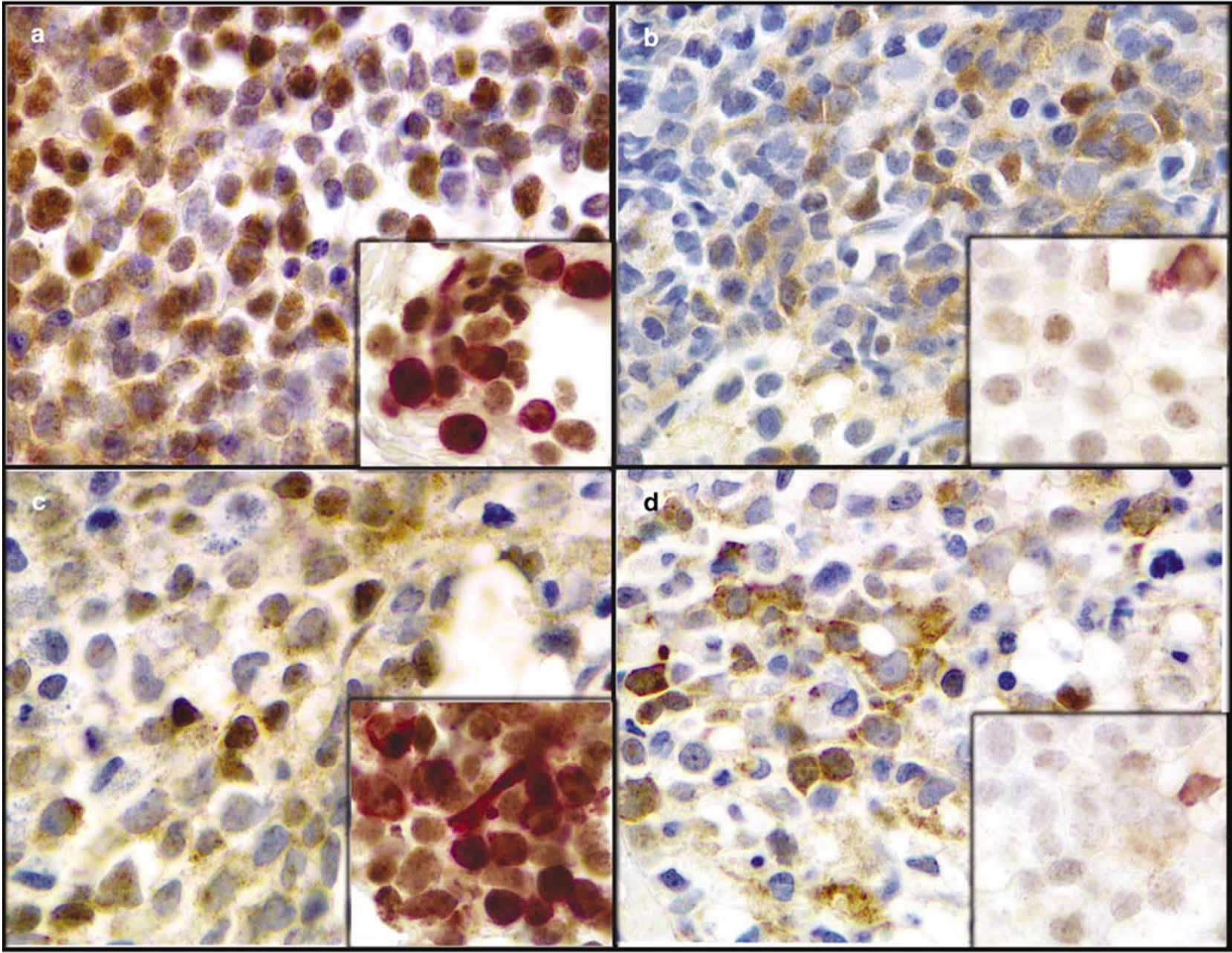

e

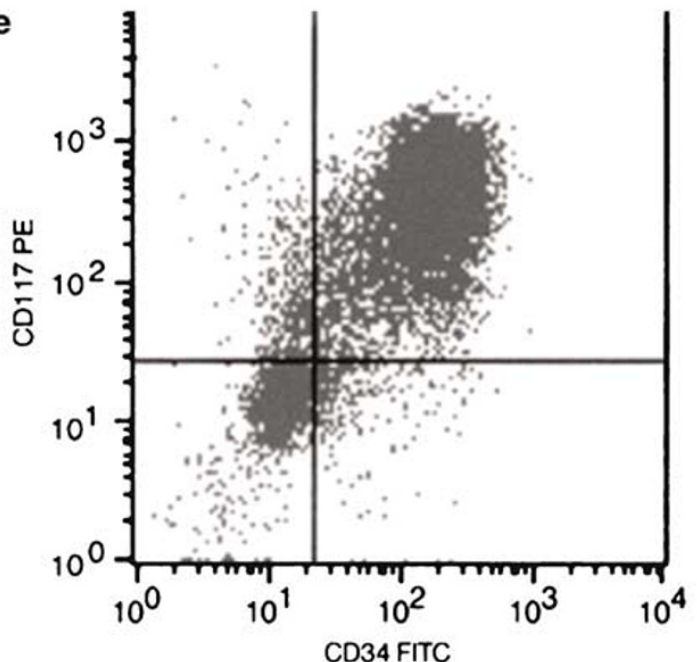

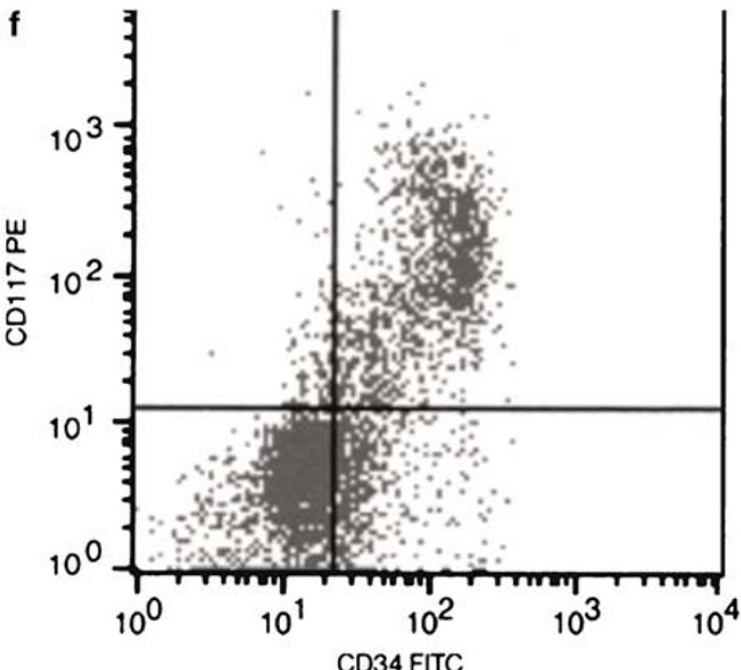

Figure 1 Expression levels of NF- $\kappa$ B p65, CCND2, and CD34 in the leukemic cells of M4Eo cases and acute myelomonocytic leukemia M4 control. (a) NF- $\kappa$ B p65 detected in a case of M4Eo. More than $80 \%$ of the blasts have intense and uniform intranuclear reactivity. (b) A case of acute myelomonocytic leukemia M4 with a high percentage of blasts in the bone marrow biopsy. Less than $10 \%$ of cells are positive for nuclear NF- $\kappa \mathrm{B}$ p65. (c and d) CCND2 expression levels in M4Eo cases and acute myelomonocytic leukemia M4 control, respectively. Note the higher nuclear CCND2 expression levels in M4Eo cells. The inserts show that more cells are positive in M4Eo cases than in acute myelomonocytic leukemia M4 control when double stained for CD34 and NF- $\kappa$ B p65 (a and b) or CCND2 (c and d). (e and f) Quantitation of CD34 and CD117 expression levels in blasts by flow cytometry. Expression levels of CD34 and CD117 were much higher in fresh BM blasts from an M4Eo case compared with acute myelomonocytic leukemia M4 control. 
Table 3 NF- $\kappa$ B p65 and CCND2 expression in M4Eo and M4 by immunohistochemistry

\begin{tabular}{lcccccc}
\hline Protein & \multicolumn{2}{c}{ M4Eo } & & \multicolumn{2}{c}{ M4 } & P-value \\
\cline { 2 - 3 } \cline { 5 - 6 } & $\begin{array}{c}\text { Median } \\
(\%)\end{array}$ & Number & $\begin{array}{c}\text { Median } \\
(\%)\end{array}$ & Number & \\
\hline NF- $\kappa$ B p65 (\%) & 37 & 49 & & 11 & 35 & $<0.001$ \\
CCND2 (\%) & 35 & 63 & & 11.5 & 30 & $<0.001$ \\
\hline
\end{tabular}

RT-PCR. In the 17 M4Eo cases tested, the CCND2 expression levels were higher (median +2.00 -fold) compared with the control (Supplementary Figure 2). Likewise, although not to the same extent, the cyclin D1 expression levels in the M4Eo cases were also higher (median +1.26-fold in the Pathway microarray) compared with the control (Supplementary Table 2b). However, the expression levels of $c y c l i n$ D3 (CCND3) in the M4Eo cases were lower in both microarrays $(-2.28$ - and -1.87 -fold in the cDNA and Pathway microarrays, respectively; Table 2c). We also performed immunohistochemical analysis for CCND2 (Figure 1c and d). Nuclear expression of CCND2 was significantly higher in the additional 63 M4Eo cases (median 35\%, range 5-82\%) compared with the additional 30 acute myelomonocytic leukemia M4 cases (median $11.5 \%$, range $1-47 \%)(P<0.001)$ (Table 3$)$.

Spermidine/spermine N1-acetyltransferase (SAT) had lower expression levels in the M4Eo cases than in the control $(-3.27$-fold on the cDNA microarray; Table 2a). Our RT-PCR data also showed that $S A T$ had lower expression levels (-0.6-fold) in the M4Eo cases (Supplementary Figure 2). Decreased expression levels of $S A T$, a rate-limiting enzyme in the catabolism of polyamines by acetylation, may lead to increased polyamine concentration. Polyamines are growth factors that are essential for neoplastic transformation and cell proliferation. ${ }^{28,29}$ Other differentially expressed genes involved in cell proliferation include $C D 34(+1.62$-fold in the Pathway microarray), CD117 (c-KIT; $+1.54-$ and +2.17 -fold in the cDNA and Pathway microarrays, respectively), amphiregulin (schwannoma-derived growth factor; -5.15-fold in the Pathway microarray), EMP1 (epithelial membrane protein 1; medians of +2.31- and +3.15-fold in the cDNA and Pathway microarrays, respectively), INSL4 (insulin-like $4 ;+2.35$-fold in the cDNA microarray), and TM4SF4 (transmembrane 4 superfamily member 4; +3.76-fold in the cDNA microarray) (Tables 2a-c).

We also compared CD117 and CD34 expression levels in 36 M4Eo cases and 40 acute myelomonocytic leukemia M4 controls by flow cytometry immunophenotyping. Figure $1 \mathrm{e}$ and $\mathrm{f}$ and Table 4 show analysis of the blast region demonstrating that the expression levels of both proteins were significantly higher in M4Eo blasts than in acute myelomonocytic leukemia M4 blasts.
Table 4 CD117 and CD34 expression in M4Eo and M4 blasts by flow cytometry immunophenotyping

\begin{tabular}{lccc}
\hline Protein & M4Eo $(\mathrm{n}=36)$ & M4 $(\mathrm{n}=40)$ & P-value \\
\hline CD117 (\%) & 94.1 & 36.1 & $<0.001$ \\
CD34 (\%) & 81.0 & 22.3 & $<0.001$ \\
\hline
\end{tabular}

\section{Genes Involved in Apoptosis are Differentially} Expressed in M4Eo Cases Compared with Control

Several apoptosis-inducing genes were downregulated in the M4Eo cases. STAT-induced STAT inhibitor-2 (STATI2), also known as the suppressor of cytokine signaling (SOCS2) ${ }^{30}$ had markedly lower expression levels in the M4Eo cases than in the control (-4.57-fold in the Pathway microarray; Table 2b). Another proapoptotic gene, DNA damageinducible transcript 3 (DDIT3), which is one of the components of the endoplasmic reticulum stressmediated apoptosis pathway and associated with cell stress and apoptosis, ${ }^{31,32}$ was also among one of the most differentially expressed genes $(-2.44$-fold in the Pathway microarray; Table 2b). Hemopoietic cell kinase (HCK), which participates in activation of kinase-dependent and caspase-mediated apoptosis, ${ }^{33}$ also had markedly lower expression levels in the M4Eo cases than in the control $(-1.82-$ and -2.45-fold in the cDNA and Pathway microarrays, respectively; Table 2c). In contrast, the anti-apoptotic gene Bcl-2 had higher expression levels in the M4Eo cases than in the control $(+1.74-$ and $+1.71-$ fold in the cDNA and the Pathway microarrays, respectively).

\section{Discussion}

We employed microarray techniques to determine the gene expression profile of 18 M4Eo cases. We confirmed some of the gene expression data by RT-PCR, immunohistochemistry, and flow cytometry immunophenotyping. We found a high level of activation of the NF- $\kappa \mathrm{B}$ signaling pathway in the M4Eo cases compared with the acute myelomonocytic leukemia M4 control.

$\mathrm{NF}-\kappa \mathrm{B}$ activation is a common component of signaling pathways involved in a wide variety of cellular processes, including cell cycle progression, apoptosis, and oncogenesis. NF- $\kappa \mathrm{B}$ can be activated by various stimuli, including cytokines and growth factors. The $\mathrm{I} \kappa \mathrm{Bs}$, a family of inhibitors, usually sequester NF- $\kappa$ B in the cytoplasm. Activation of NF$\kappa \mathrm{B}$ involves phosphorylation of $\mathrm{I} \kappa \mathrm{Bs}$ by $\mathrm{I} \kappa \mathrm{B}$ kinase, which leads to the destruction of $\mathrm{I} \kappa \mathrm{Bs}$ and allows translocation of NF- $\kappa \mathrm{B}$ to the nucleus (see review by Ravi and $\mathrm{Bedi}^{34}$ ). Our results strongly suggest that the NF- $\kappa$ B pathway is activated at a higher level in M4Eo than in acute myelomonocytic leukemia M4. $N F \kappa B I A$, the gene that encodes $\mathrm{I} \kappa \mathrm{B} \alpha,{ }^{23}$ an NF- $\kappa \mathrm{B}$ inhibitor, was downregulated, as was TNFAIP3, 
another NF- $\kappa$ B inhibitor. ${ }^{24}$ Conversely, TNFRSF11a and TNFRSF11b, two of the tumor necrosis factor receptor superfamily members, were upregulated. It is known that NF- $\kappa \mathrm{B}$ can be activated by TNFRs and that TNFRSF11a is a RANK. ${ }^{25,26}$ Consistent with these microarray gene expression data, our immunohistochemical results showed that the nuclear immunoreactivity of NF- $\kappa \mathrm{B}$ p65, an activated form of NF- $\kappa \mathrm{B}$, was significantly higher in the M4Eo cases than in the acute myelomonocytic leukemia M4 control.

Increased cell proliferation and decreased apoptosis are among the main consequences of NF- $\kappa \mathrm{B}$ activation. Our previous studies showed that M4Eo cases have a high rate of proliferation but a low rate of apoptosis, as indicated by high bone marrow cellularity, brisk tumor cell mitosis, high positivity for Ki-67 (an indicator of growth fraction), and rarity of tumor cells positive for terminal deoxynucleotidyl transferase-mediated dUTP-nick end labeling, an assay for apoptosis. ${ }^{11}$ Members of the cyclin D family are the main regulators of the G1/S transition in the cell cycle and have been found to be elevated in some malignant cells. ${ }^{35}$ We found that cyclin D1 and D2 were both upregulated in M4Eo cases, again suggesting high proliferation status in M4Eo. Radosevic et $a l^{36}$ reported that expression levels of CCND2 were lower in acute monocytic leukemias (FAB M4 and M5) than in other types of acute myeloid leukemia (FAB M0, M1, and M2). Unfortunately, no M4Eo cases were included in their study. High expression levels of cyclin D1 and D2 may be directly or indirectly related to $\mathrm{NF}-\kappa \mathrm{B}$ activation because the cyclin $D 1$ promoter region contains an NF- $\kappa \mathrm{B}$ binding site. ${ }^{37}$ Interestingly, we found that cyclin D3 was downregulated in M4Eo cases and was among the top differentially expressed genes. This is not surprising considering the inhibitory process triggered by $C B F \beta-M Y H 11$ in M4Eo; CBF $\beta$-MYH11 inhibits AML-1, which usually binds to and activates the cyclin D3 promoter. ${ }^{38}$

$N F-\kappa \mathrm{B}$ can mediate a variety of survival signals that protect cells from apoptosis. ${ }^{34} B c l-X L$, an antiapoptotic Bcl-2 family member, contains an $\mathrm{NF}-\kappa \mathrm{B}$ binding site in its promoter. Unfortunately, we could not assess Bcl-XL expression in M4Eo in our study because it was not present in either of the microarrays used. However, we found that $\mathrm{BCl}-2$ had a higher expression level in M4Eo cases than in the control in both microarrays. It is interesting that several proapoptotic genes, such as STATI2, are downregulated in M4Eo. STATI2 encodes a member of the gene family known as the STATinduced STAT inhibitor ( $S S I$ ) or the suppressor of cytokine signaling (SOCS). ${ }^{30}$ STATI2 is a cytokineinducible negative regulator, and its proapoptotic effect balances the proliferative effect of cytokine signaling. ${ }^{39}$ Downregulation of STATI2 apparently allows proliferation to overweigh apoptosis in M4Eo.
The high expression levels of CD117 (the c-KIT receptor) in all the M4Eo cases assessed in the present study is of interest. c-KIT Asp816 mutations have been reported in $7.9 \%$ of patients with M4Eo; $c$-KIT exon 8 mutations, which are exclusively detected in $23.8 \%$ of adult de novo acute myeloid leukemia with inv(16) patients, result in activation of the CD117 receptor and are associated with an increased relapse rate. ${ }^{40}$ High expression levels of CD117 suggest that CBF $\beta$-MYH11 might be involved in modulating the function of the c-KIT receptor.

In summary, we determined the gene expression profile of M4Eo using two microarrays and acute myelomonocytic leukemia M4 cases as a control. The gene expression profile of M4Eo suggests a highly activated NF- $\kappa$ B pathway, a high proliferative status, and a low apoptotic status, all of which are likely to result from the coordinated effects of a constellation of genes directly or indirectly affected by the chimeric protein CBF $\beta$-MYH11. High expression levels of NF- $\kappa \mathrm{B}$ p65 also suggest that targeting $\mathrm{NF}-\kappa \mathrm{B}$ is a therapeutic strategy for patients with M4Eo.

\section{Acknowledgements}

This project was supported by a fellow research funding award from the Division of Pathology and Laboratory Medicine at MD Anderson to XS, an Olla Stribling fund to CBR, National Cancer Institute Cancer Center Support Grant 5P30 CA016672-28, the Tobacco Settlement Fund to MD Anderson as appropriated by the Texas legislature, and funds from the Kadoorie Foundation to the Genomics Facility. We thank Martin $\mathrm{H}$ Nguyen and Ellen Taylor for their excellent technical assistance. We thank Ann Sutton for her editorial suggestions. We also thank Ana M Martinez for her secretarial support.

\section{References}

1 Brunning RD, Matutes E, Flandrin G, et al. Acute myeloid leukaemia with recurrent genetic abnormalities. In: Jaffe ES, Harris NL, Stein H, Vardiman JW (eds). World Health Organization Classification of Tumours. Pathology and Genetics. Tumours of Haematopoietic and Lymphoid Tissues, IARC Press: Lyon, France, 2001, pp 82-84.

2 Bennett JM, Catovsky D, Daniel MT, et al. Proposed revised criteria for the classification of acute myeloid leukemia. A report of the French-American-British cooperative group. Ann Intern Med 1985;103:620-625.

3 Le Beau MM, Larson RA, Bitter MA, et al. Association of an inversion of chromosome 16 with abnormal marrow eosinophils in acute myelomonocytic leukemia. A unique cytogenetic-clinicopathological association. N Engl J Med 1983;309:630-636.

4 Bitter MA, Le Beau MM, Larson RA, et al. A morphologic and cytochemical study of acute myelo- 
monocytic leukemia with abnormal marrow eosinophils associated with inv(16)(p13q22). Am J Clin Pathol 1984;81:733-741.

5 Bernard P, Dachary D, Reiffers J, et al. Acute nonlymphocytic leukemia with marrow eosinophilia and chromosome 16 abnormality: a report of 18 cases. Leukemia 1989;3:740-745.

6 Liu P, Tarle SA, Hajra A, et al. Fusion between transcription factor CBF beta/PEBP2 beta and a myosin heavy chain in acute myeloid leukemia. Science 1993;261:1041-1044.

7 Liu PP, Wijmenga C, Hajra A, et al. Identification of the chimeric protein product of the CBFB-MYH11 fusion gene in inv(16) leukemia cells. Genes Chromosomes Cancer 1996;16:77-87.

8 Kanto S, Chiba N, Tanaka Y, et al. The PEBP2beta/CBF beta-SMMHC chimeric protein is localized both in the cell membrane and nuclear subfractions of leukemic cells carrying chromosomal inversion 16. Leukemia 2000;14:1253-1259.

9 Haferlach $\mathrm{T}$, Winkemann $\mathrm{M}$, Loffler $\mathrm{H}$, et al. The abnormal eosinophils are part of the leukemic cell population in acute myelomonocytic leukemia with abnormal eosinophils (acute myeloid leukemia M4Eo) and carry the pericentric inversion 16: a combination of May-Grunwald-Giemsa staining and fluorescence in situ hybridization. Blood 1996; 87:2459-2463.

10 Marlton P, Keating M, Kantarjian H, et al. Cytogenetic and clinical correlates in acute myeloid leukemia patients with abnormalities of chromosome 16. Leukemia 1995;9:965-971.

11 Sun X, Medeiros LJ, Lu D, et al. Dysplasia and high proliferation rate are common in acute myeloid leukemia with inv(16)(p13q22). Am J Clin Pathol 2003;120:236-245.

12 Wong KF, Kwong YL. Trisomy 22 in acute myeloid leukemia: a marker for myeloid leukemia with monocytic features and cytogenetically cryptic inversion 16. Cancer Genet Cytogenet 1999;109:131-133.

13 Kundu M, Chen A, Anderson S, et al. Role of Cbfb in hematopoiesis and perturbations resulting from expression of the leukemogenic fusion gene CbfbMYH11. Blood 2002;100:2449-2456.

14 Shigesada K, van de Sluis B, Liu PP. Mechanism of leukemogenesis by the inv(16) chimeric gene CBFB/ PEBP2B-MHY11. Oncogene 2004;23:4297-4307.

15 Valk PJ, Verhaak RG, Beijen MA, et al. Prognostically useful gene-expression profiles in acute myeloid leukemia. N Engl J Med 2004;350:1617-1628.

16 Bullinger L, Dohner K, Bair E, et al. Use of geneexpression profiling to identify prognostic subclasses in adult acute myeloid leukemia. $N$ Engl J Med 2004;350:1605-1616.

17 Monica K, Galili N, Nourse J, et al. PBX2 and PBX3, new homeobox genes with extensive homology to the human proto-oncogene PBX1. Mol Cell Biol 1991;11:6149-6157.

18 Liu PP, Hajra A, Wijmenga C, et al. Molecular pathogenesis of the chromosome 16 inversion in the M4Eo subtype of acute myeloid leukemia. Blood 1995;85:2289-2302.

19 Zhao W, Claxton DF, Medeiros LJ, et al. Immunohistochemical analysis of CBFbeta-SMMHC protein reveals a unique nuclear localization in acute myeloid leukemia with inv(16)(p13q22). Am J Surg Pathol 2006;30:1436-1444.
20 Kirchner J, Bevan MJ. ITM2A is induced during thymocyte selection and $\mathrm{T}$ cell activation and causes downregulation of CD8 when overexpressed in CD4(+)CD8(+) double positive thymocytes. J Exp Med 1999;190:217-228.

21 Van den Plas D, Merregaert J. Constitutive overexpression of the integral membrane protein Itm2A enhances myogenic differentiation of C2C12 cells. Cell Biol Int 2004;28:199-207.

22 Van den Plas D, Merregaert J. In vitro studies on Itm2a reveal its involvement in early stages of the chondrogenic differentiation pathway. Biol Cell 2004;96: $463-470$.

23 Senftleben U, Karin M. The IKK/NF-kappaB pathway. Crit Care Med 2002;30:S18-S26.

24 Wertz IE, O’Rourke KM, Zhou H, et al. De-ubiquitination and ubiquitin ligase domains of A20 downregulate NF-kappaB signalling. Nature 2004;430: 694-699.

25 Anderson DM, Maraskovsky E, Billingsley WL, et al. A homologue of the TNF receptor and its ligand enhance T-cell growth and dendritic-cell function. Nature 1997;390:175-179.

26 Galibert L, Tometsko ME, Anderson DM, et al. The involvement of multiple tumor necrosis factor receptor (TNFR)-associated factors in the signaling mechanisms of receptor activator of NF-kappaB, a member of the TNFR superfamily. J Biol Chem 1998;273: 34120-34127.

27 Bueso-Ramos CE, Rocha FC, Shishodia S, et al. Expression of constitutively active nuclear-kB RelA transcription factor in blasts of acute myeloid leukemia. Hum Pathol 2004;35:246-253.

28 Scorcioni F, Corti A, Davalli P, et al. Manipulation of the expression of regulatory genes of polyamine metabolism results in specific alterations of the cellcycle progression. Biochem J 2001;354:217-223.

29 Ignatenko NA, Babbar N, Mehta D, et al. Suppression of polyamine catabolism by activated Ki-ras in human colon cancer cells. Mol Carcinog 2004;39: 91-102.

30 Wormald S, Hilton DJ. Inhibitors of cytokine signal transduction. J Biol Chem 2004;279:821-824.

31 Oyadomari S, Mori M. Roles of CHOP/GADD153 in endoplasmic reticulum stress. Cell Death Differ 2004;11:381-389.

32 Kilberg MS, Barbosa-Tessmann IP. Genomic sequences necessary for transcriptional activation by amino acid deprivation of mammalian cells. J Nutr 2002;132: 1801-1804.

33 Shivakrupa R, Radha V, Sudhakar C, et al. Physical and functional interaction between Hck tyrosine kinase and guanine nucleotide exchange factor C3G results in apoptosis, which is independent of C3G catalytic domain. J Biol Chem 2003;278: 52188-52194.

34 Ravi R, Bedi A. NF-kappaB in cancer-a friend turned foe. Drug Resist Updat 2004;7:53-67.

35 Furukawa Y. Cell cycle control genes and hematopoietic cell differentiation. Leuk Lymphoma 2002;43: 225-231.

36 Radosevic N, Delmer A, Tang R, et al. Cell cycle regulatory protein expression in fresh acute myeloid leukemia cells and after drug exposure. Leukemia 2001;15:559-566.

37 Guttridge DC, Albanese C, Reuther JY, et al. NF-kappaB controls cell growth and differentiation through 
transcriptional regulation of cyclin D1. Mol Cell Biol 1999;19:5785-5799.

38 Bernardin-Fried F, Kummalue $\mathrm{T}$, Leijen $\mathrm{S}$, et al. Acute myeloid leukemia 1/RUNX1 increases during G1 to $S$ cell cycle progression independent of cytokine-dependent phosphorylation and induces cyclin D3 gene expression. J Biol Chem 2004;279: 15678-15687.
39 Faderl S, Harris D, Van Q, et al. Granulocyte-macrophage colony-stimulating factor (GM-CSF) induces antiapoptotic and proapoptotic signals in acute myeloid leukemia. Blood 2003;102:630-637.

40 Care RS, Valk PJ, Goodeve AC, et al. Incidence and prognosis of c-KIT and FLT3 mutations in core binding factor (CBF) acute myeloid leukaemias. Br J Haematol 2003;121:775-777.

Supplementary Information accompanies the paper on Modern Pathology website (http://www.nature.com/ modpathol) 